\title{
Una revisión sistemática de los patógenos virales y bacterianos de aves silvestres en Chile
}

\section{A systematic revision of viral and bacterial pathogens of free-ranging wild birds in Chile}

Daniel González-Acuña ${ }^{*}$ Dr. Med. Vet. y Sebastián Llanos-Soto ${ }^{1,2}$ M.V.

'Laboratorio de Parásitos y Enfermedades de Fauna Silvestre, Facultad de Ciencias Veterinarias Universidad de Concepción. Concepción, Chile.

${ }^{2}$ Laboratorio de Vida Silvestre. Departamento de Ciencia Animal. Facultad de Ciencias Veterinarias, Universidad de Concepción. Concepción, Chile.

Conflictos de interes: ninguno que declarar

Financiamiento: Proyecto FONDECYT 1170972

Recibido (segunda versión): 15 de noviembre de 2019 / Aceptado: 17 de julio de 2020

\section{Resumen}

El conocimiento acerca de agentes patógenos presentes en aves silvestres es crucial para la apropiada prevención de eventos de transmisión que puedan afectar a la salud pública y animal. Esta revisión sistemática organiza toda la información disponible acerca de los patógenos virales y bacterianos de las aves silvestres chilenas, determina qué patógenos y órdenes de aves han recibido atención reciente por parte de la comunidad científica local, evalúa cambios en la frecuencia de publicación de artículos e identifica brechas en el conocimiento respecto a estos patógenos. Un total de 35 artículos revisados por pares han sido publicados desde enero de 1941 hasta abril de 2019. Agentes virales fueron evaluados en 11 estudios, mientras que 24 concernieron a bacterias. Los artículos científicos se han publicado mayormente de forma discontinua en años previos al 2006. Salmonella spp. e influenza aviar han sido los patógenos más estudiados con 10 y 8 estudios, respectivamente. Las regiones de Los Ríos y Valparaíso concentran el mayor número de estudios y no se ha realizado investigación en las regiones de O’Higgins, Maule y Aysén. En general, la información acerca de patógenos en aves silvestres es escasa, por lo que es necesario incrementar los esfuerzos para identificar patógenos portados por reservorios aviares y evaluar el riesgo potencial que pueden representar para la conservación de fauna silvestre, producción animal y el sistema de salud pública en Chile.

Palabras clave: aviar; Chile; bacterias; aves; virus; zoonosis.

\section{Abstract}

Knowledge about pathogenic agents present in wild birds is pivotal to properly prevent transmission events that might threaten public and animal health. This systematic review organizes all information available about viral and bacterial pathogens of Chilean wild birds, determines which pathogens and avian orders have received attention from the local scientific community, evaluates changes in the frequency of article publication, and identifies gaps in knowledge regarding these pathogens. A total of 35 peer-reviewed publications have been published from January 1941 through April 2019. Viral agents were evaluated in 11 studies, while 24 involved bacteria. Article publication has been mostly discontinuous in years prior to 2006. Salmonella spp. and avian influenza have been the most studied pathogens with 10 and 8 studies, respectively. Los Ríos and Valparaíso regions concentrate the highest number of studies and no research has been carried out in O'Higgins, Maule, and Aysén regions. Overall, information about pathogens in wild birds is scarce, highlighting the need for increased effort to identify pathogens being carried by avian reservoirs and evaluate the potential threat that they might pose for wildlife conservation, animal production, and the public health system in Chile.

Keywords: avian; Chile; birds; bacteria; virus; zoonoses. 


\section{Material y Métodos}

Se incluyeron en el estudio especies de aves nativas e introducidas de vida libre. Los estudios sobre animales domésticos y animales mantenidos en cautiverio en zoológicos, centros de exposición y granjas no fueron incluidos en esta revisión. También se excluyeron las publicaciones referidas al territorio antártico chileno, ya que otros trabajos se han centrado en este tema ${ }^{11,12}$. Las aves se consideraron chilenas cuando su distribución reproductiva o en reposo se encontraba dentro del territorio chileno, incluidas Rapa Nui e islas oceánicas. Las especies cuya distribución está restringida a la Antártica y las islas sub-antárticas (es decir, Pygoscelis adeliae y Aptenodytes forsteri) o su presencia en Chile ha sido esporádica o restringida a un solo registro (por ejemplo, Streptoprocne zonaris, Porphyrio martinicus, Mycteria americana) fueron excluidas de esta revisión. Además, un organismo bacteriano o viral fue clasificado como patógeno e incluido en esta revisión si había información disponible en la literatura científica que indicaba su capacidad para causar enfermedades en animales, humanos o ambos. Así mismo, en esta revisión sólo se incluyeron publicaciones revisadas por pares y se excluyeron los datos entregados por medio de literatura gris (es decir, libros, tesis, resúmenes en conferencias científicas y/o seminarios).

La búsqueda y listado de artículos científicos revisados por pares que evalúan la presencia de patógenos virales y bacterianos en aves chilenas fue realizada siguiendo las indicaciones de la declaración de Elementos de informe preferidos para revisiones sistemáticas y meta-análisis PRISMA (Preferred Reporting Items for Systematic Reviews and Meta-Analyses) ${ }^{13}$.

Las publicaciones científicas revisadas por pares sobre patógenos virales y bacterianos en aves silvestres chilenas se recopilaron en los buscadores académicos Google Scholar (https://scholar.google.cl/), Scielo Scientific Library (http://www.scielo.org/) y PubMed (https://www. ncbi.nlm.nih.gov/pubmed/). Las búsquedas se realizaron utilizando las siguientes palabras claves: "aviar", "aves silvestres" Y "Actinobacter", "adenovirus", "ántrax", "arbovirus", "bacterias", "Chlamydophila", "Chlamydia", "Clostridium", "virus de la anemia del pollo", "circovirus", "coronavirus", "plaga del pato", "Erysipelothrix", "Escherichia coli", "Helicobacter", "herpesvirus", "enfermedad infecciosa de la bursa", "Gumboro" "influenza", "Listeria", "Mycobacterium", "Mycoplasma", "Newcastle", "papillomavirus", "paramixovirus", "Pasteurella", "polyomavirus", "poxvirus", "retrovirus", "Salmonella", "tularemia", "viral", "virus", "virus del Nilo Occidental" Y "Chile". Estos mismos términos fueron traducidos al inglés para realizar la búsqueda de artículos científicos en literatura publicada en ese idioma. 
Esta revisión consideró todas las publicaciones existentes en la literatura científica, en este caso desde enero de 1941 hasta abril de 2019.

La información recopilada de las publicaciones seleccionadas se organizó en un archivo hoja Excel (Microsoft $^{\circledR}$ Excel 2010) con datos sobre la especie hospedadora aviar, la prevalencia de patógenos, las técnicas de diagnóstico y la caracterización de patógenos. Esto último considera la variante antigénica, el linaje genético, el serogrupo o la localización de serovares, dependiendo del analisis empleado durante el estudio. Sin embargo, es importante considerar que algunos estudios, particularmente aquellos más antiguos, no presentaban este tipo de información.

Los estudios científicos que realizaron análisis moleculares de infecciones confirmadas previamente también se incluyeron en esta revisión. Las publicaciones que no estaban disponibles para descargar en línea fueron buscadas físicamente por los autores o solicitadas por correo electrónico a bibliotecarios en las bibliotecas de la Universidad de Chile, la Pontificia Universidad Católica de Chile, la Universidad Austral y la Universidad de Concepción.

\section{Resultados}

Los resultados de la búsqueda arrojaron un total de 35 publicaciones revisadas por pares que incluían el estudio de patógenos virales y/o bacterianos en aves silvestres chilenas. Se recopiló información para 11 estudios que evaluaron agentes virales, mientras que 24 se referían a bacterias. Los detalles sobre cada patógeno incluido en la revisión se detallan en la Tabla 1. El agente viral más estudiado fue la influenza aviar con ocho artículos científicos. En el caso de las bacterias, Salmonella spp. se abordó en diez artículos, mientras que Campylobacter spp. se evaluó en seis estudios. Las publicaciones sobre patógenos virales y bacterianos en aves silvestres chilenas han sido, en su mayoría, discontinuas en los años anteriores a 2006, con una ausencia de estudios entre los años 1991 a 1994 y 2000 a 2005. Los artículos sobre virus se han mantenido bajos a lo largo de los años, con un máximo de dos publicaciones en los años 2012 y 2015.

Se investigaron patógenos en un total de 40 especies de aves incluidas en los órdenes Charadriifromes [n: 11], Anseriformes [n: 7], Strigiformes [n: 4], Suliformes [n: 3], Accipitriformes [n: 2], Cathartiformes [n: 3], Columbiformes [n: 2], Pelecaniformes [n: 2], Falconiformes [n: 2], Sphenisciformes [n: 2], Passeriformes [n: 1] y Gruiformes [n: 1]. De todos los estudios sobre patógenos bacterianos incluidos en esta revisión, 11 se relacionaron con Charadriiformes, cuatro con Sphenisciformes, los ordenes Columbiformes y Suliformes se incluyeron en tres estudios cada uno, en Anseriformes y Passeriformes dos estudios cada uno, y sólo un estudio ha sido realizado en los ordenes Pelecaniformes, Accipitriformes, Falconiformes, Strigiformes y Gruiformes (Figura 1). En el caso de estudios con virus, tres estudios incluyeron Charadriiformes, dos estudios abarcan a los Cathartiformes y Anseriformes, y Columbiformes, Pelecaniformes, Accipitriformes, Falconiformes, Strigiformes, Gruiformes y Suliformes se evaluaron en un solo estudio (Figura 2). Los Passeriformes están ampliamente presentes en los entornos naturales y urbanos de Chile y pertenecen a más de la mitad de las especies presentes en Chile; sin embargo, la única especie estudiada de este orden fue el gorrión (Passer domesticus) ${ }^{14,15}$.

El orden Charadriiformes ha recibido gran atención en Chile con 13 publicaciones científicas que han evaluado ocho tipos de patógenos. Las gaviotas dominicanas y las gaviotas Franklin son las especies más estudiadas, cada una con siete estudios que han analizado patógenos bacterianos y dos estudios que han evaluado virus. El orden Columbiformes se ha evaluado en cinco estudios, mientras que Anseriformes y Falconiformes se han incluído en cuatro publicaciones. El resto de los órdenes de aves presentes en Chile fueron evaluadas en tres o menos estudios científicos. En ningún estudio sobre enfermedades infecciosas se han incluido especies de los órdenes Rheiformes, Phoenicopteriformes, Tinamiformes, Podicipediformes, Procellariformes, Phaethontiformes, Ciconiiformes, Galliformes, Psittaciformes, Cuculiformes, Caprimulgiformes, Apodiformes, Coraciiformes y Piciformes.

Las regiones con más estudios en el país han sido la Región de Los Ríos y Valparaíso, con ocho estudios cada una. También se han realizado investigaciones en las siguientes regiones: Biobío [n: 7], Arica y Parinacota [n: 5], Metropolitana [n: 4], Coquimbo [n: 3], Magallanes [n: 3], Nuble [n: 3], Araucanía [n: 2], Antofagasta [n: 2], Tarapacá [n: 1], Atacama [n: 1] y Los Lagos [n: 1]. No se han realizado estudios en las regiones de O'Higgins, Maule y Aysén.

El análisis molecular y la serología fueron los métodos más utilizados para la identificación y caracterización de patógenos virales, con cinco estudios para cada método. Sólo un estudio ha utilizado métodos histopatológicos para determinar la presencia de un patógeno viral (viruela aviar ${ }^{16}$. El cultivo bacteriano, utilizado en 17 estudios, ha sido el método más usado para el reconocimiento de patógenos bacterianos. En contraste, los métodos moleculares se utilizaron en 12 estudios, seis de los cuales los utilizaron en combinación con cultivos bacterianos y sólo un estudio utilizó combinación de cultivos bacterianos, histopatología y métodos moleculares. Sólo un estudio realizó serología para evaluar la exposición a Chlamydia (Chlamydophila) psittaci en palomas ${ }^{17}$. 


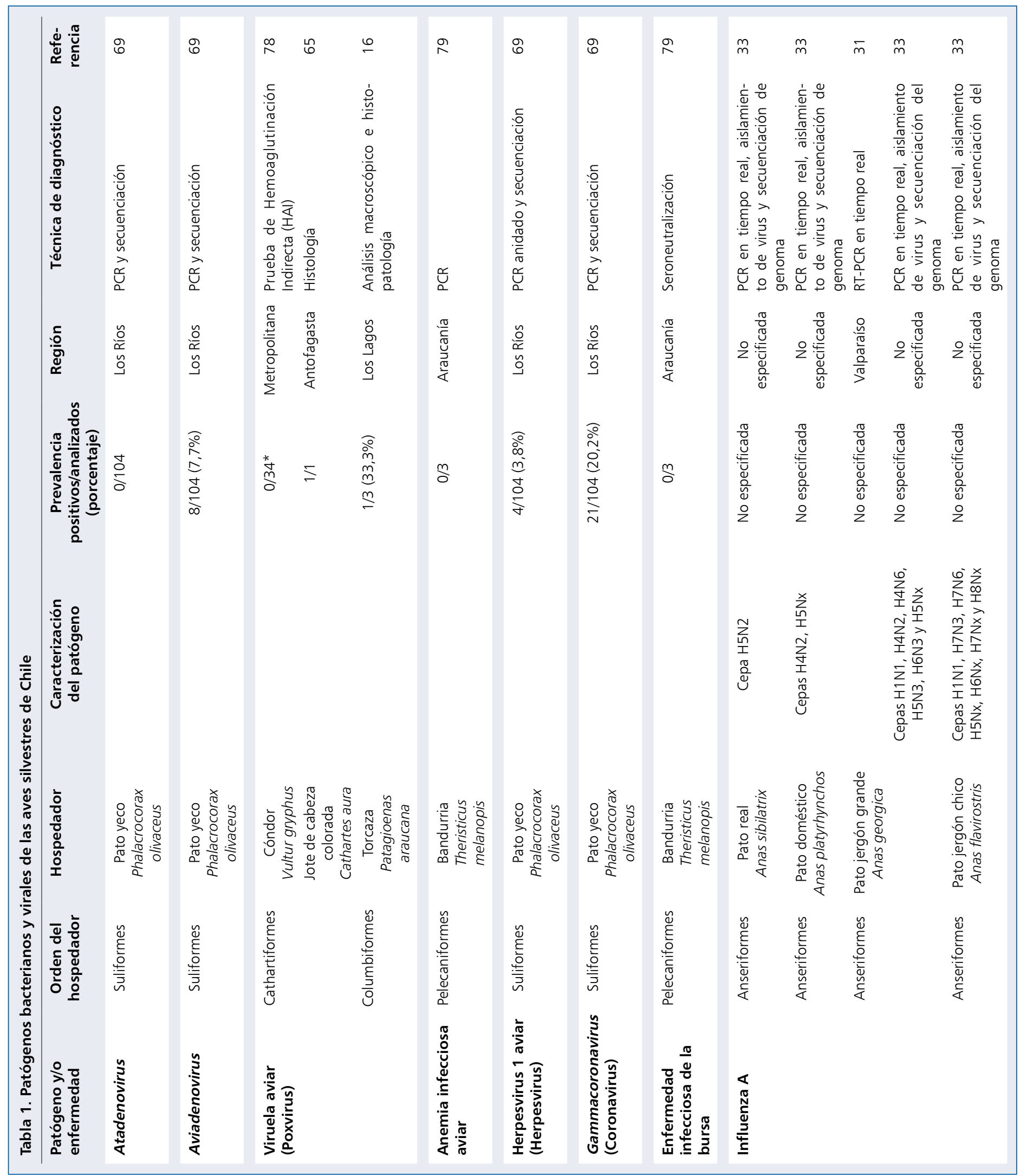




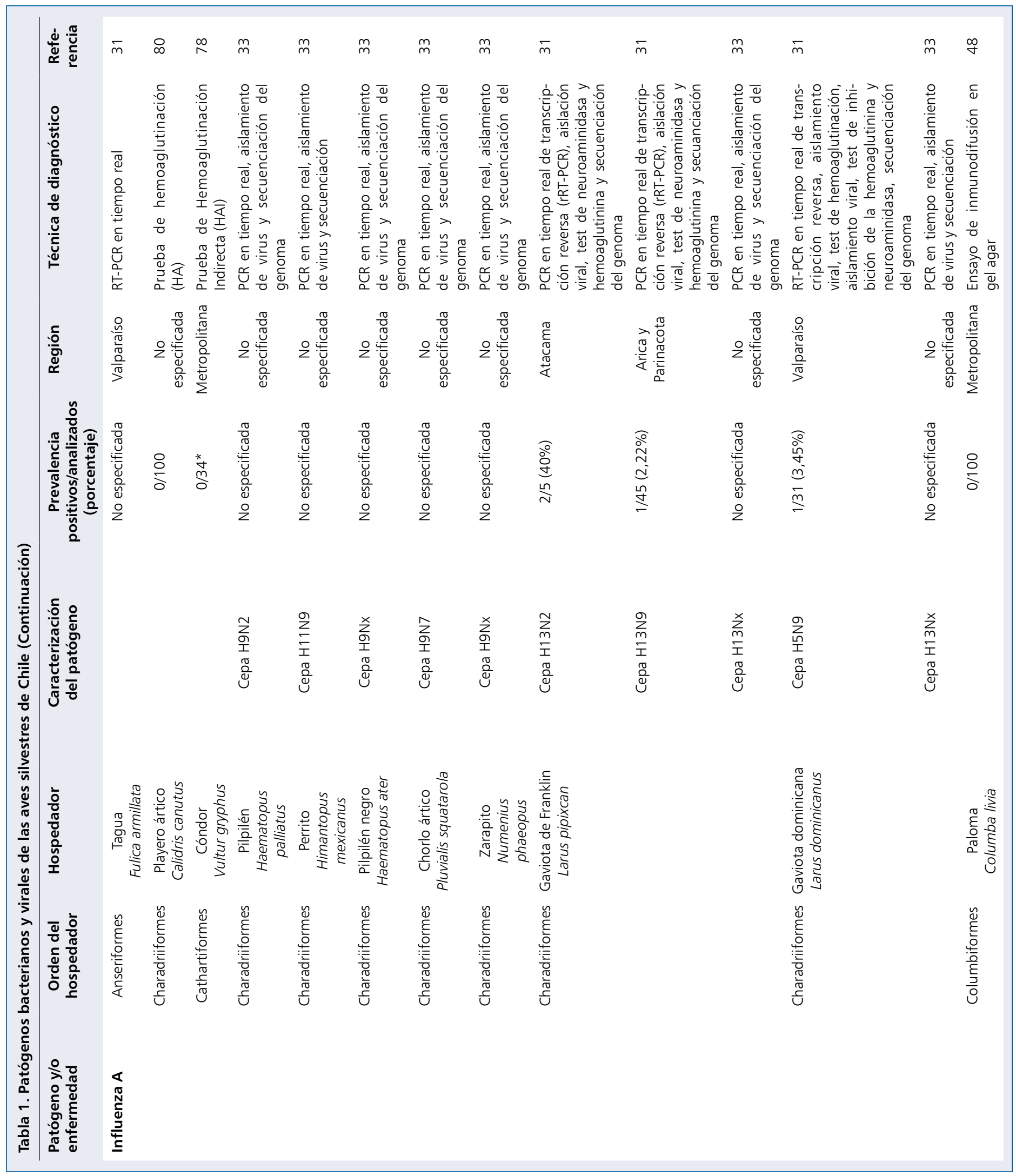




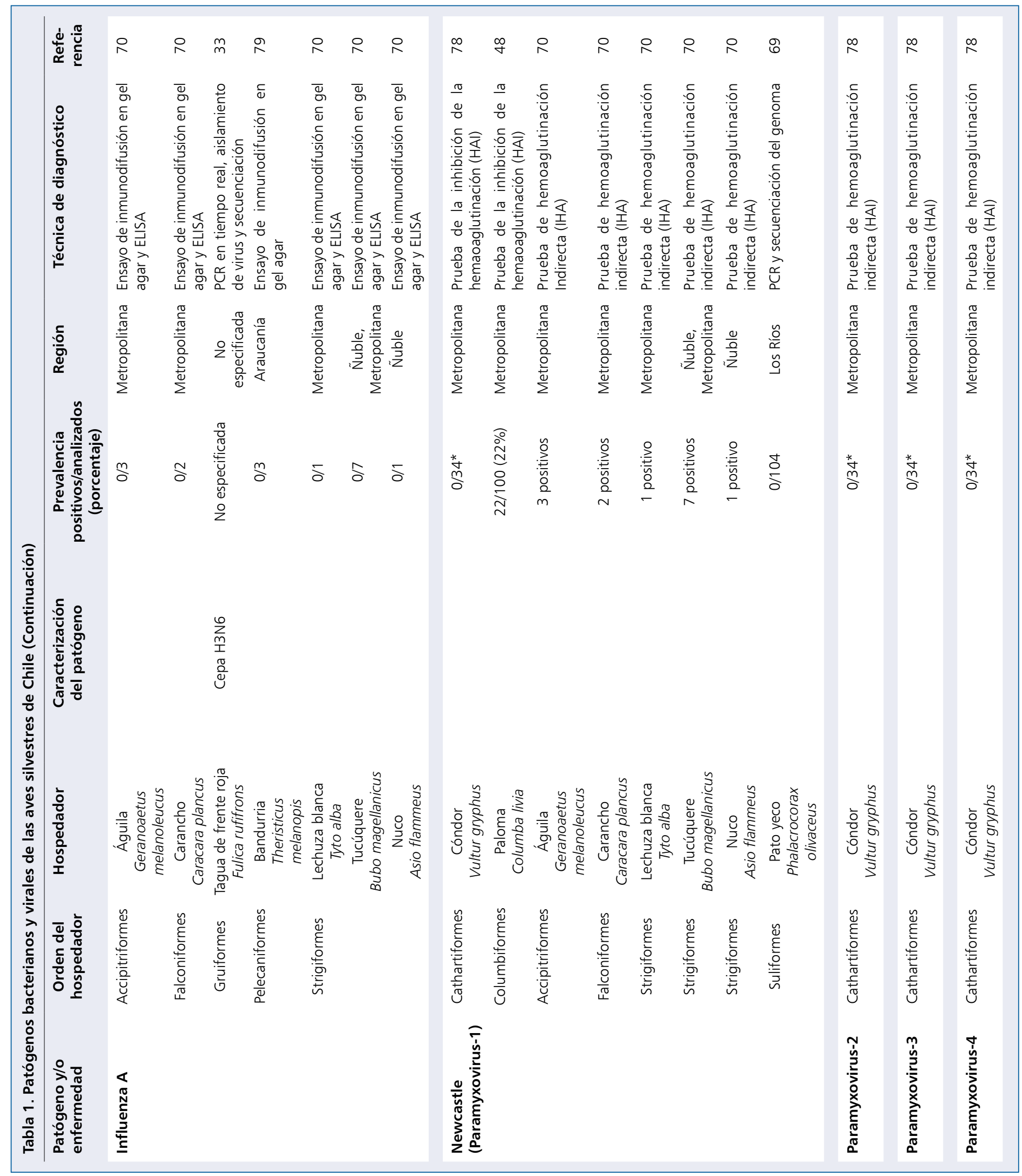




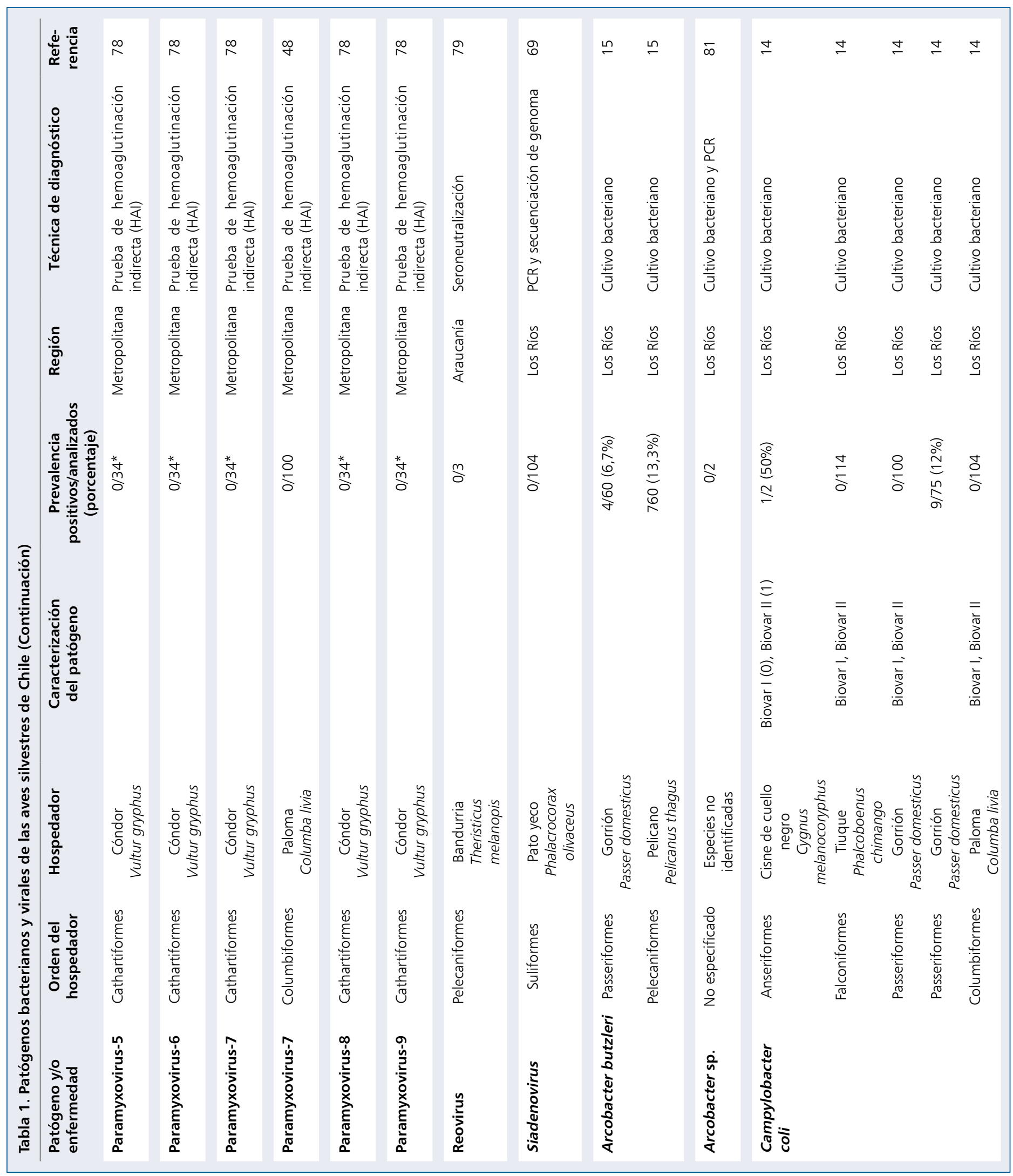




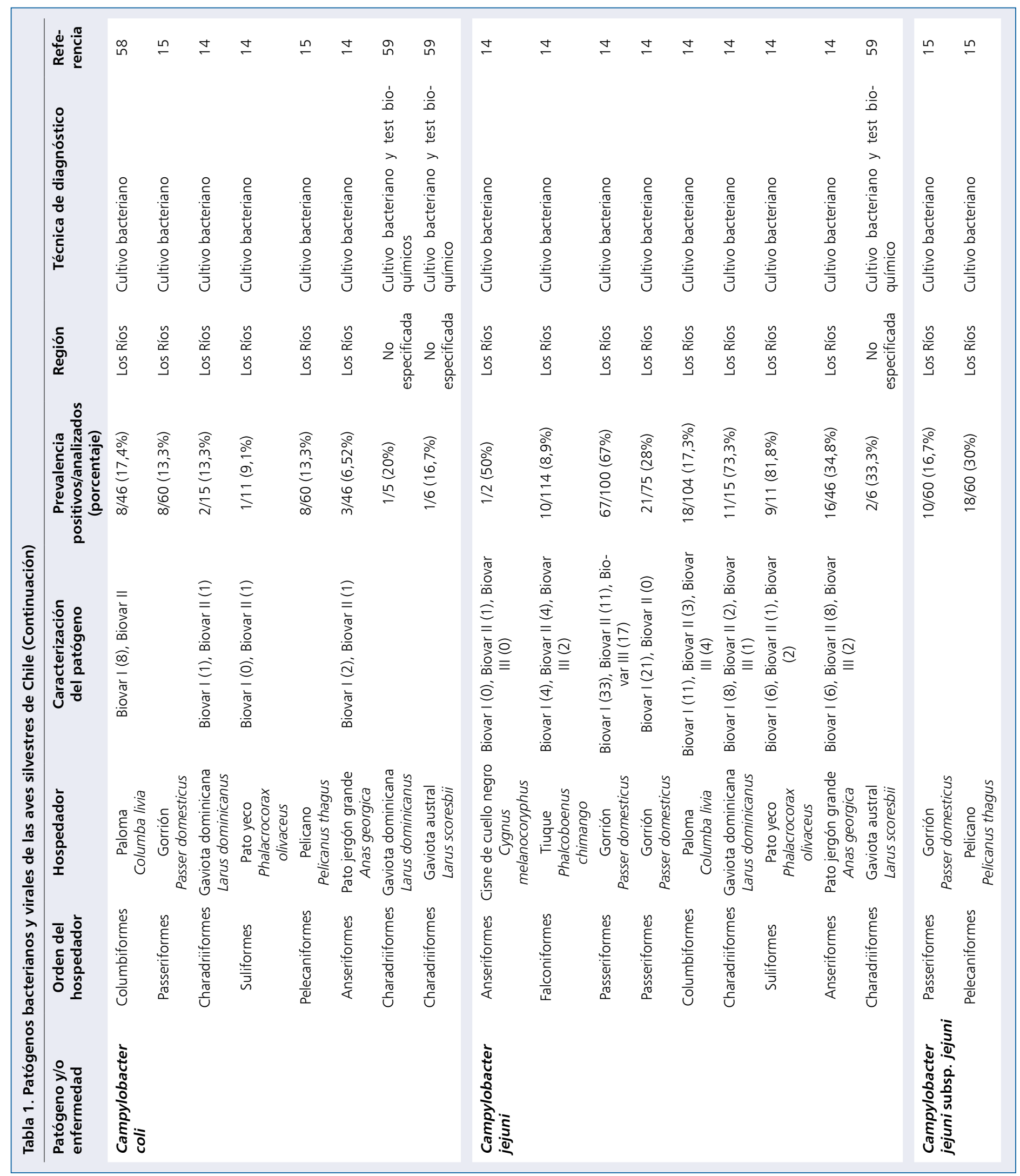




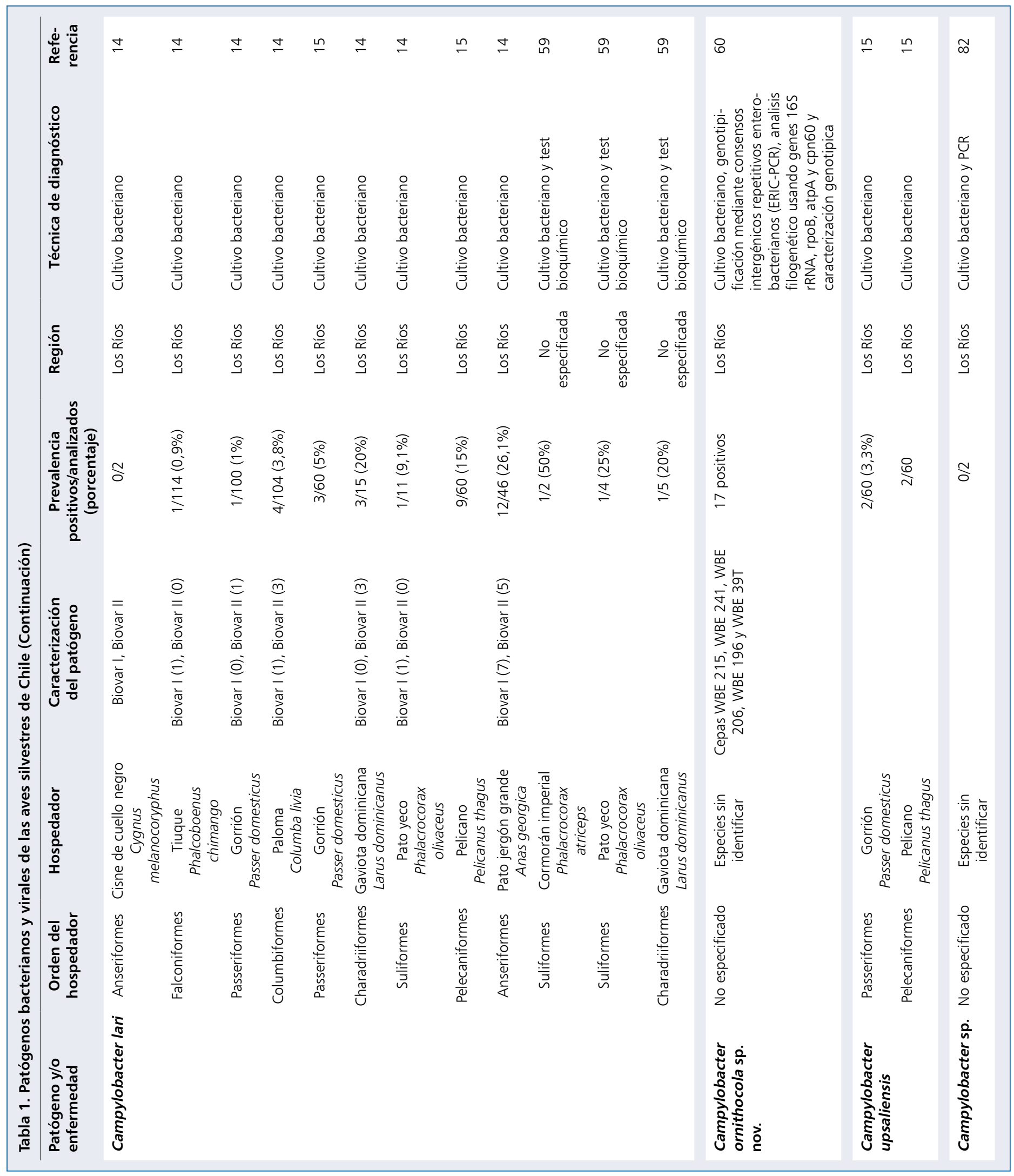




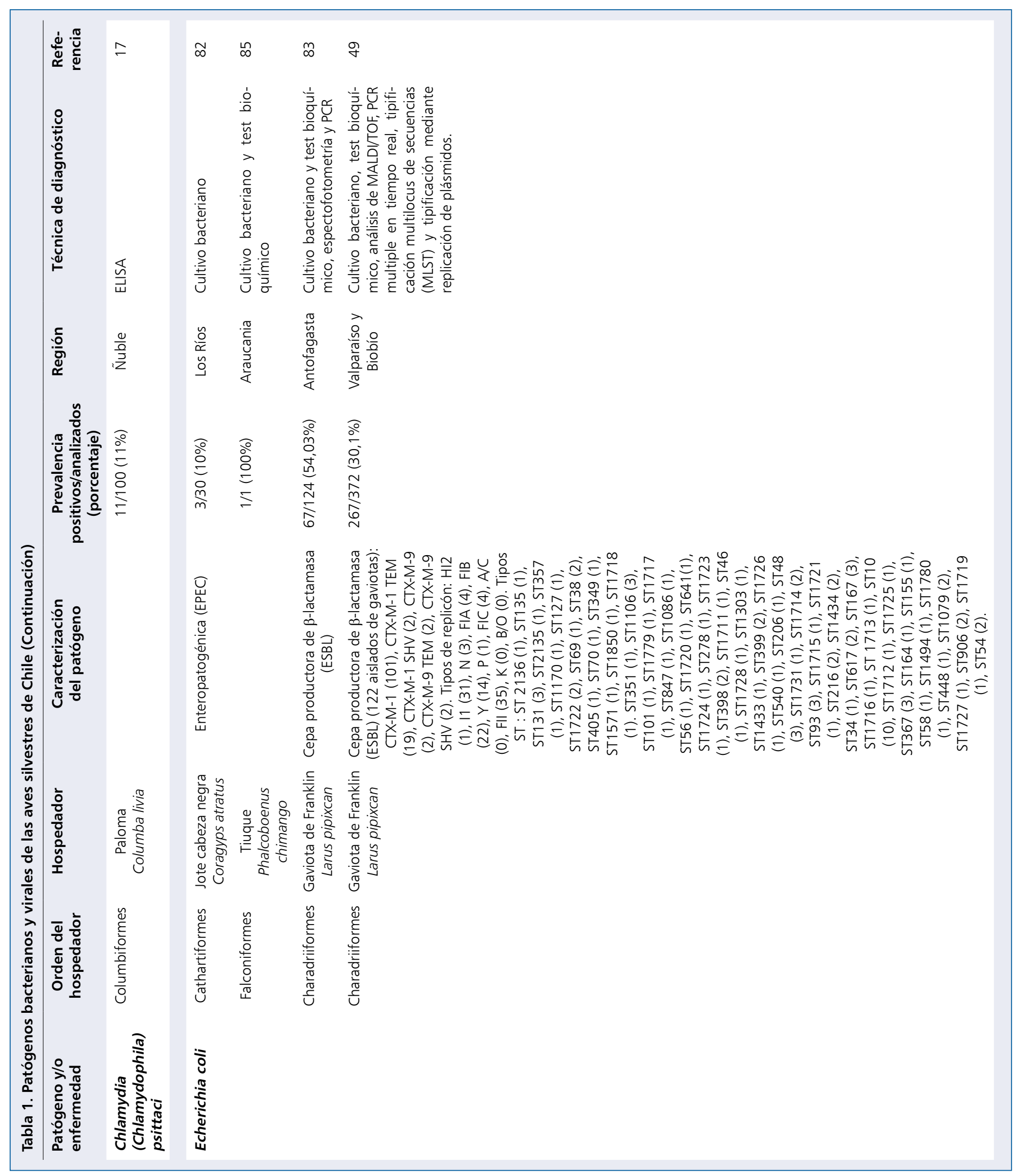




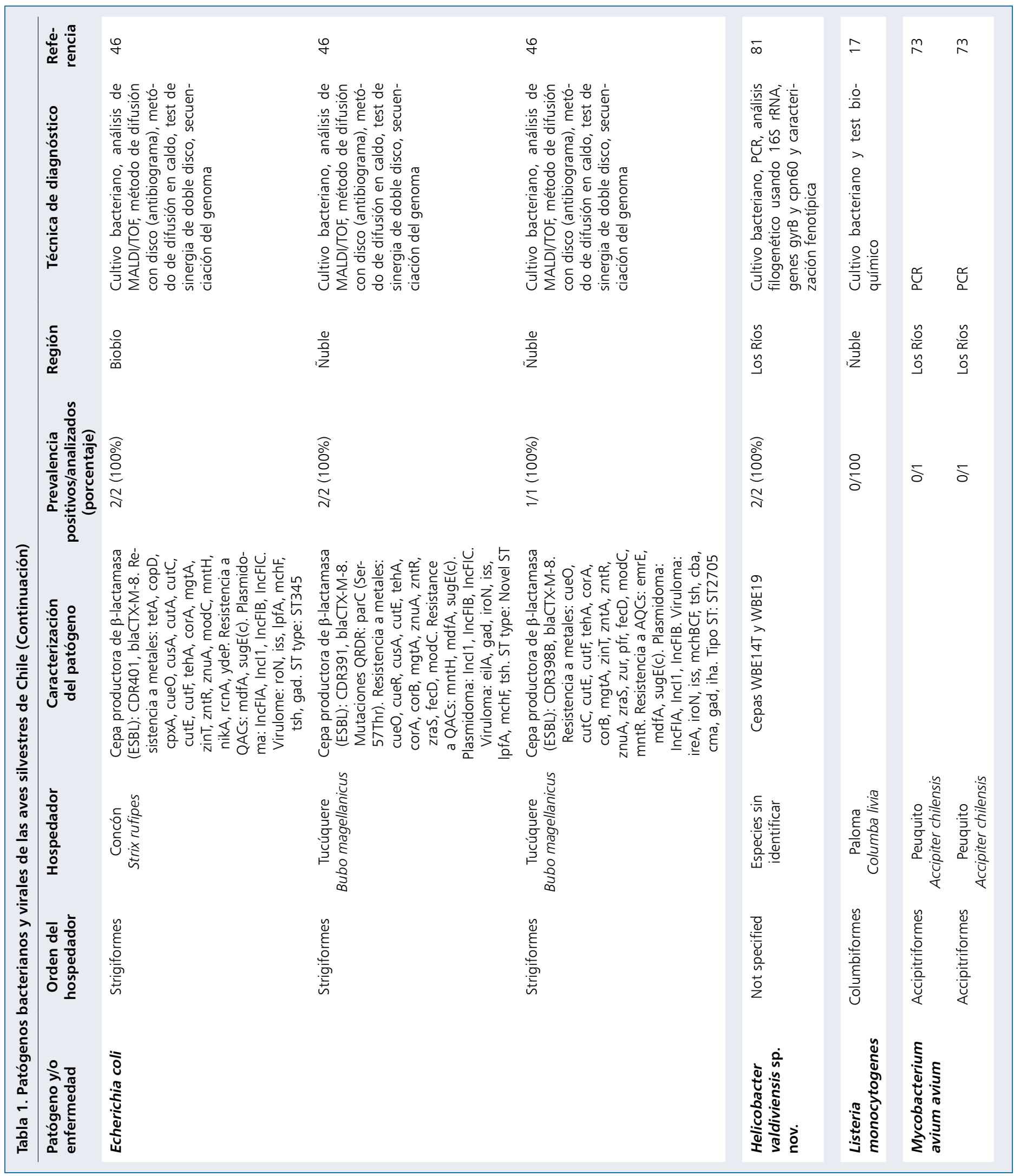




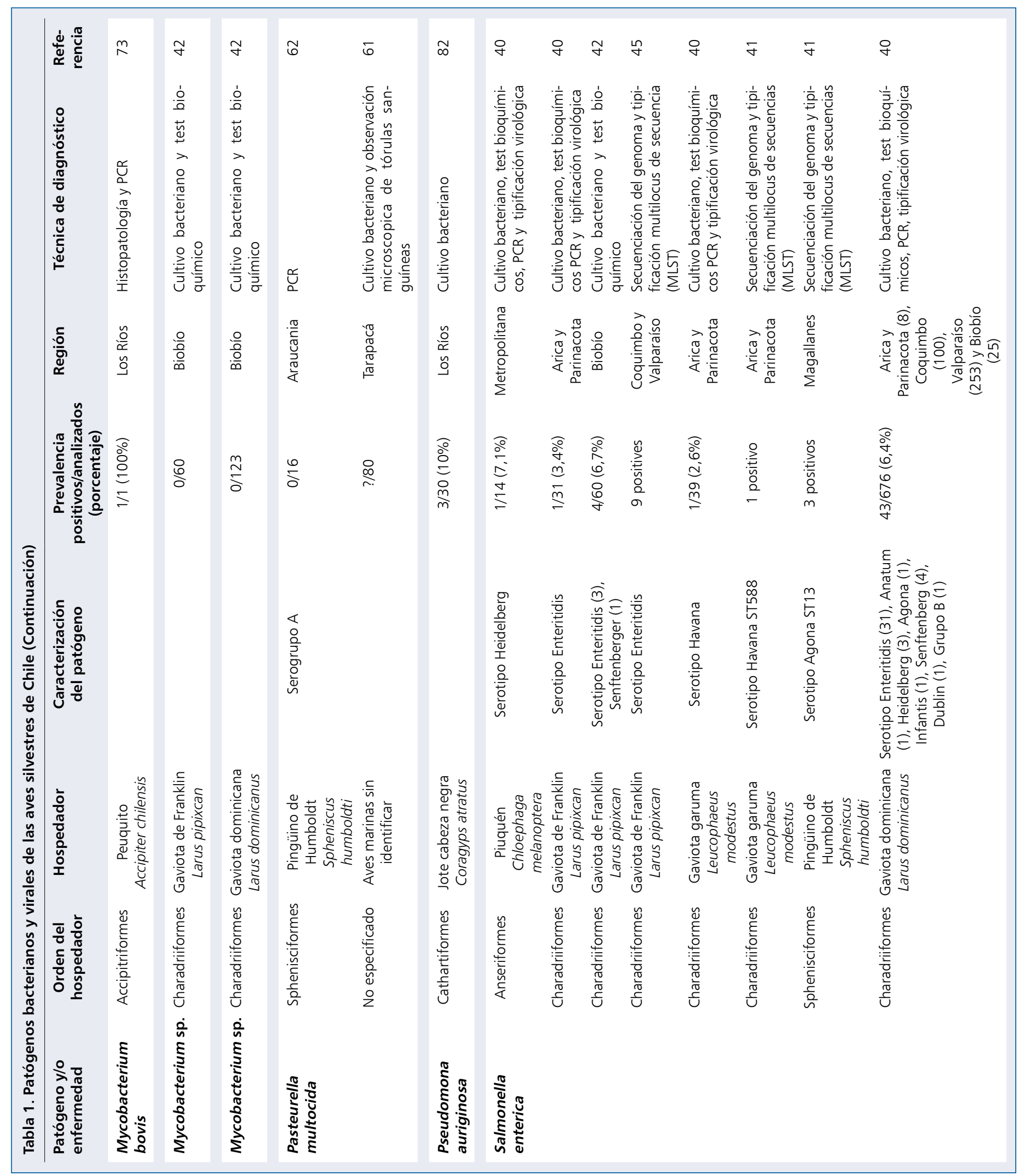




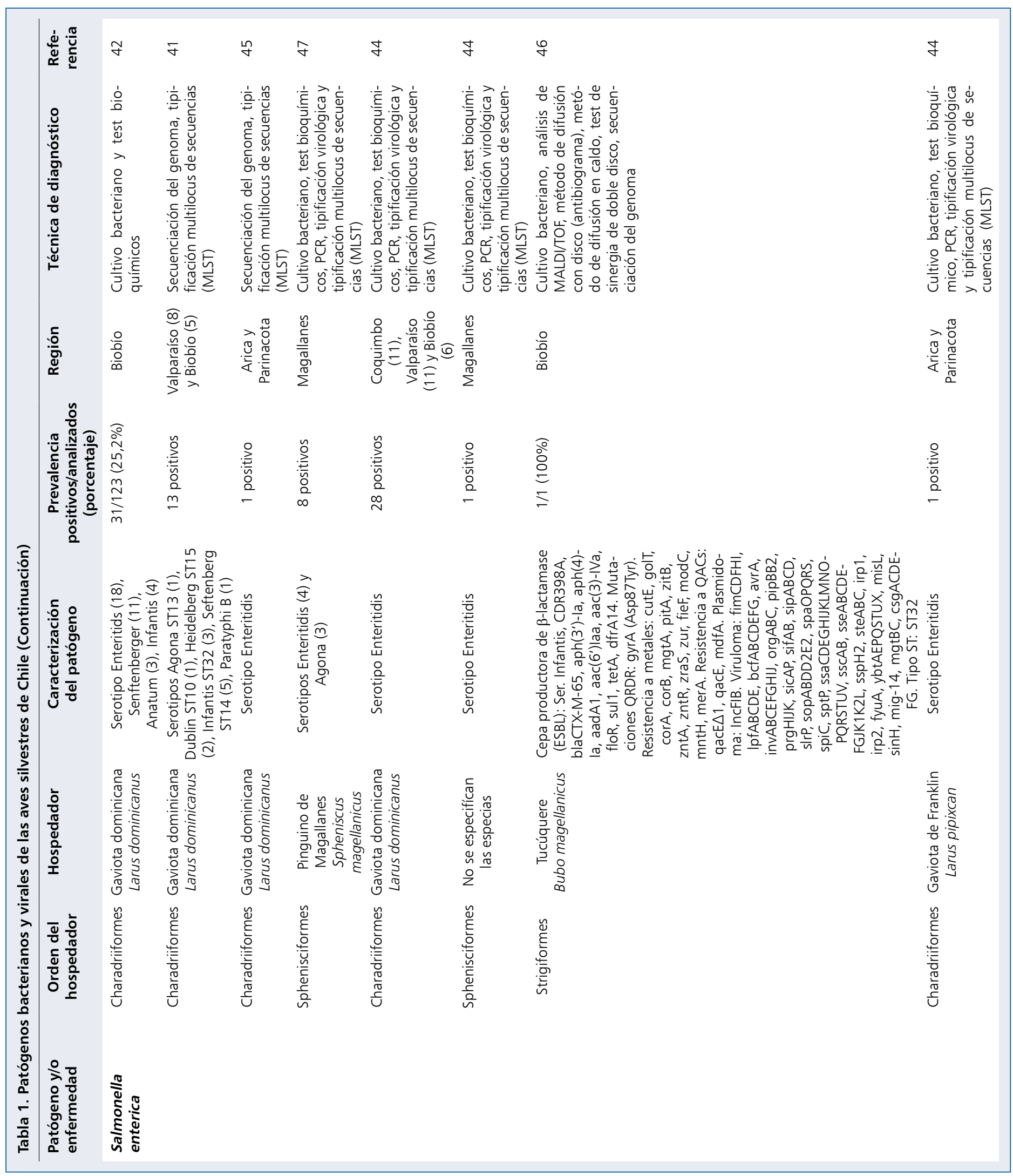




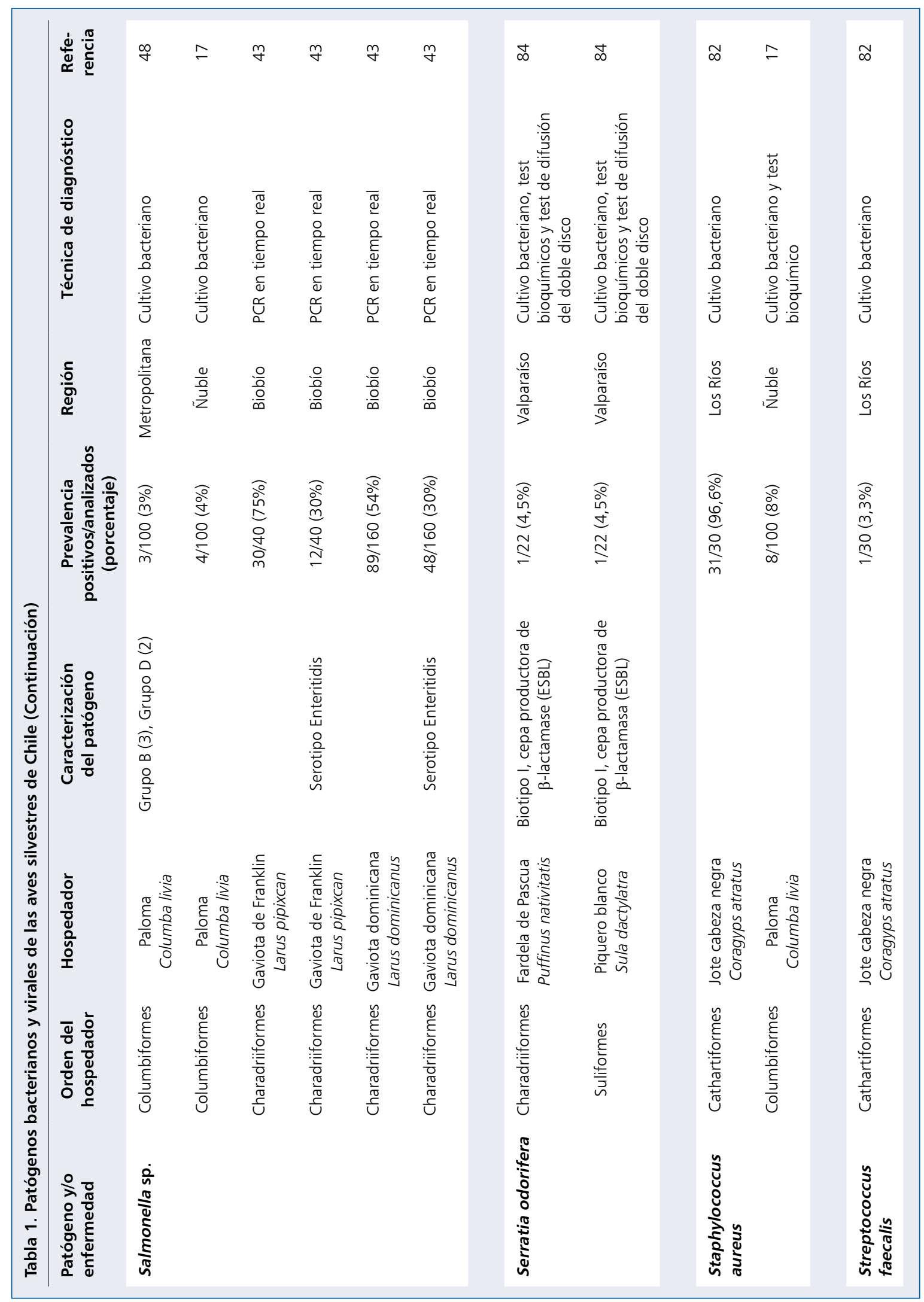




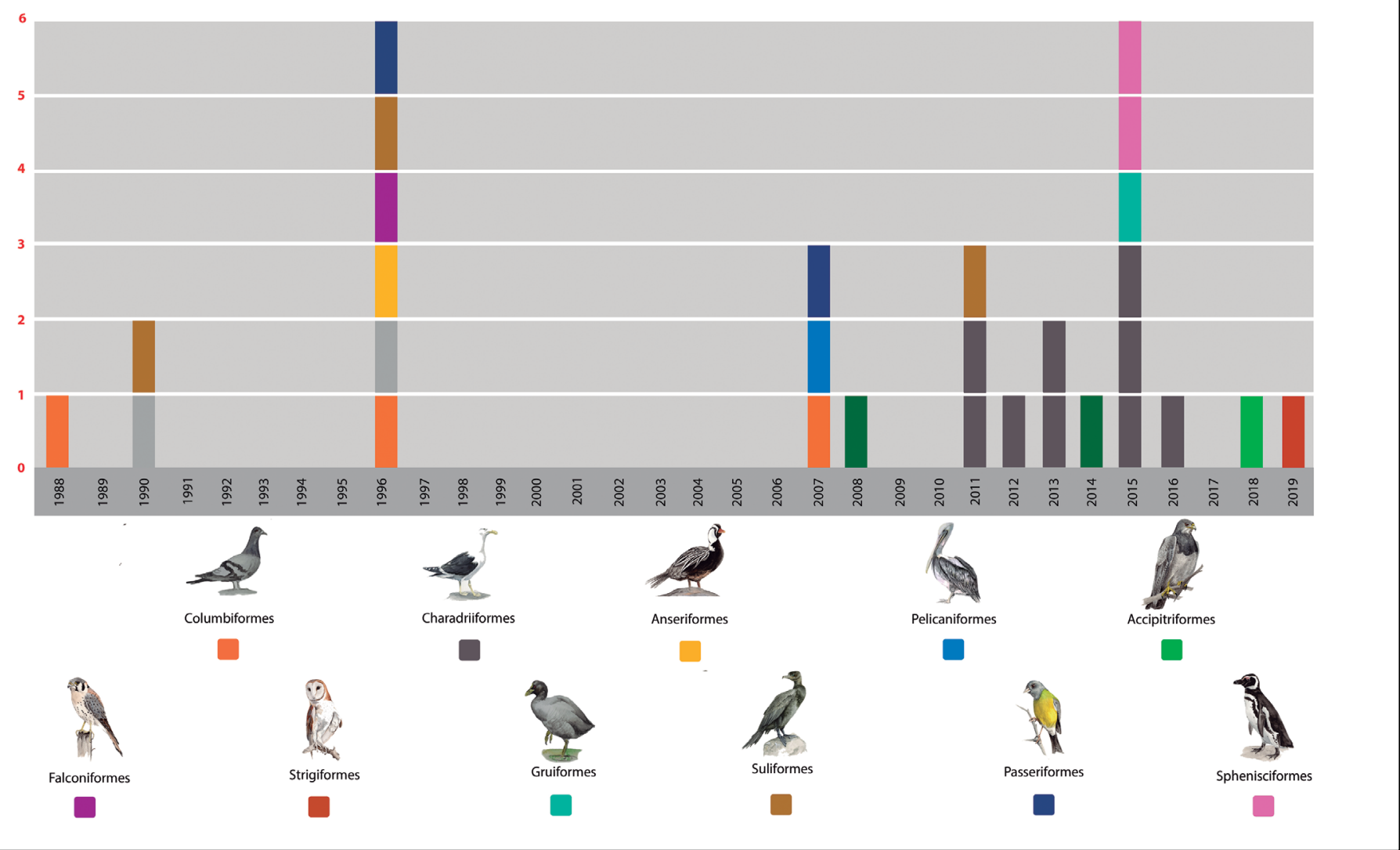

Figura 1. Número de estudios científicos que han evaluado la presencia de patógenos bacterianos en especies de aves silvestres en Chile desde 1988 hasta 2019.

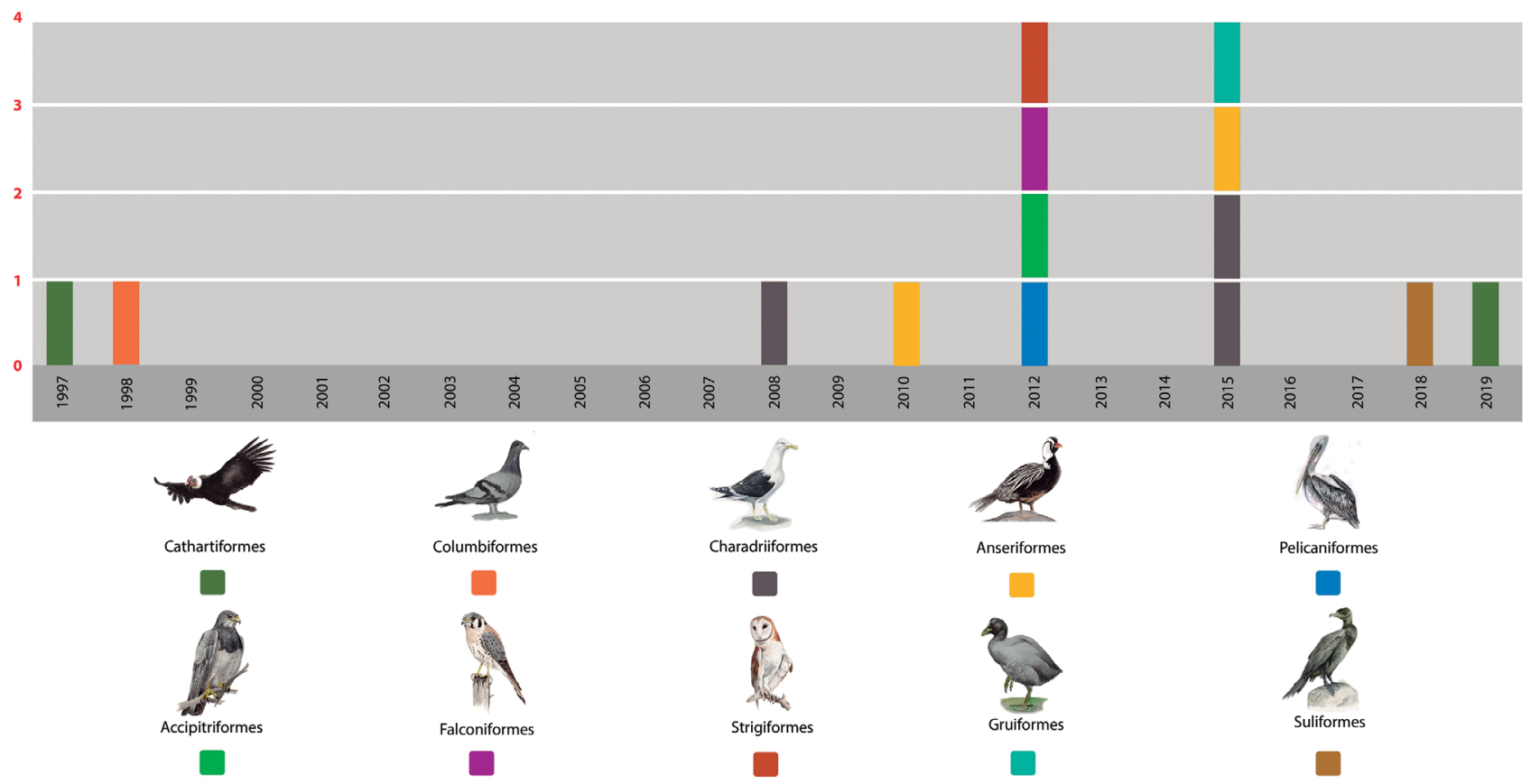

Figura 2. Número de estudios científicos que han evaluado la presencia de patógenos virales en especies de aves silvestres en Chile desde 1997 hasta 2019. 


\section{Discusión}

La comunidad científica en Chile se ha centrado en evaluar patógenos en aves silvestres que representan una amenaza para la salud humana y los sistemas de producción animal, tales como influenza aviar y Salmonella spp. En contraste, los agentes patógenos restringidos a las especies de aves silvestres han sido ignorados en su mayoría con sólo unas pocas excepciones.

A pesar de haber sido publicada en una revista revisada por pares, la información contenida en Bullock $(1956)^{18}$ sobre el ántrax en jotes de cabeza colorada (Cathartes aura) y los jotes de cabeza negra (Coragyps atratus), se consideró anecdótica e imprecisa, por lo que se excluyó de esta revisión.

\section{Influenza aviar}

La influenza aviar es un virus de la familia Orthomyxoviridae, considerado un patógeno extremadamente relevante para la salud pública, la producción animal y la conservación de la vida silvestre ${ }^{19,20}$. Las aves silvestres generalmente actúan como reservorios de los virus de la influenza aviar de baja patogenicidad (LPAIV) y, en algunos casos, también pueden participar en el mantenimiento de los virus de la influenza aviar de alta patogenicidad (HPAIV) ${ }^{20,21}$. Las aves acuáticas, tanto aves dulceacuicolas como aves marinas, son los reservorios más comunes de virus de influenza aviar en todo el mundo ${ }^{22}$. La transmisión del virus de aves acuáticas a los animales domésticos y humanos podría significar un rápido cambio evolutivo para el virus a través de la recombinación (es decir, la mezcla de genes de dos o más virus de influenza aviar) y conducir a brotes de enfermedades ${ }^{23}$.

Los primeros brotes de influenza aviar en América del Sur ocurrieron en una granja de pollos de engorda en Chile en mayo de $2002^{24}$. Este brote fue considerado un LPAI del subtipo H3N7 que se cree que se originó a partir de aves acuáticas, aunque la fuente específica no fue confirmada ${ }^{24}$. Un año antes del brote en Chile, se identificó un aislado estrechamente relacionado con la influenza aviar en el pato colorado (Spatula cyanoptera) de Bolivia, lo que sugiere que el virus podría haber viajado a Chile a través de un ave migratoria y luego diseminarse a las especies locales ${ }^{25,26}$. En junio de 2002, se produjo un segundo brote en la misma granja avícola, pero esta vez el antiguo virus LPAI adquirió características de un virus de alta patogenicidad IAAP, causando importantes pérdidas económicas y perjudicando la salud pública en el país ${ }^{24,27}$. Otro evento de brote de influenza aviar se produjo en granjas de pavos en Chile en 2009 , con aves que mostraron síntomas similares a un $\mathrm{LPAI}^{28}$. Recientes hallazgos han demostrado que las aves silvestres, en efecto, transmiten la influenza aviar a las aves de corral en Chile, particularmente en los sistemas productivos de patio ${ }^{29}$. Jiménez-Bluhm y cols., $(2019)^{30}$ determinan que el origen del foco de LPAI registrado a fines de 2016 en pavos domésticos en la Región de Valparaíso proviene de aves silvestres. Ellos logran caracterizar propiedades genéticas y antigénicas del virus y realizan una transmisión experimental en gallinas de abasto.

Hasta la fecha, los únicos estudios que informaron la presencia del virus de la influenza aviar en aves silvestres chilenas fueron realizados por Mathieu y cols. $(2015)^{31}$, y Jiménez-Bluhm y cols. $(2018)^{33}$. En ambos casos, los diagnósticos fueron hechos por técnicas moleculares y, en el caso del estudio de Mathieu y cols., se realizó además aislamiento viral (Tabla 1). En la última década se ha encontrado este virus en diferentes años y localidades, por lo que es importante el estudio continuo de este virus ya que puede diseminarse a poblaciones productivas tal como lo detallan Mathieu y cols. (2019) ${ }^{32}$. Los resultados de sus contribuciones indican la presencia de influenza aviar en gaviotas Franklin's (Larus pipixcan), gaviotas dominicanas (Larus dominicanus) ${ }^{31}$, pilpilén (Haematopus palliatus), perrito (Himantopus mexicanus), pilpilén negro (Haemantopus ater), pato real (Anas sibilatrix), chorlo ártico (Pluvialis squatarola), pato de collar (Anas platyrhynchos), tagua de frente roja (Fulica rufifrons), zarapito (Numenius phaeopus), pato jergon grande (Anas georgica) y pato jergon chico (Anas flavirostris) ${ }^{33}$. Los aislados encontrados en aves distribuidas en el norte de Chile fueron genéticamente similares a los que circulan en aves acuáticas del este, centro y oeste de América del Norte. Sin embargo, una amplia variedad de subtipos de virus de influenza aviar presentes en aves silvestres del centro y sur de Chile eran exclusivas de América del Sur, lo que llevó a Jiménez-Bluhm y cols. $(2018)^{33}$, a sugerir que el número de linajes de influenza de América del Norte podría disminuir en latitudes más altas. El país se considera libre de influenza aviar altamente patogéna, no obstante, en los últimos años se ha visto afectado por diferentes brotes de virus influenza de baja patogenicidad.

\section{Salmonella spp}

Salmonella es un patogeno zoonótico de importancia para la salud pública en todo el mundo, responsable de alrededor de 1.300 millones de casos de enfermedad entérica en humanos cada año ${ }^{34}$. Las aves generalmente actúan como portadores asintomáticos de Salmonella; sin embargo, se han registrado casos de mortalidad en pequeños paseriformes ${ }^{35}$. En Chile, casos de Salmonella enterica serotipo Enteritidis comenzaron a registrarse en 1994; sin embargo, la gran mayoría de los diagnósticos de diferentes serotipos de Salmonella han sido realizados a partir del año 2011 y actualmente 
están incluidos en el programa nacional de vigilancia, tanto en animales domésticos como en humanos ${ }^{36}$. Los serovares de Salmonella prevalentes en el país son Enteritidis y Typhimurium, aunque en la mayoría de los casos el agente causal no ha sido identificado ${ }^{37,38}$. Los programas de vigilancia en animales se centran principalmente en sistemas avícolas intensivos y no consideran la evaluación de Salmonella en animales silvestres ${ }^{37}$. Este hecho resulta preocupante debido a la importancia que tienen las aves silvestres en el mantenimiento de Salmonella en el medio ambiente y su papel en la transmisión a los animales domésticos y humanos ${ }^{39}$.

Estudios de aves silvestres chilenas han encontrado Salmonella en el piuquén (Chloephaga melanoptera $)^{40}$, gaviota garuma (Leucophaeus modestus) $)^{40,41}$, gaviota Franklin (Larus pipixcan) ${ }^{40,42,43,44,45}$, pingüino de Humboldt (Spheniscus humboldti) ${ }^{41}$, pingüino de Magallanes (Spheniscus magellanicus) $)^{47}$, gaviotas dominicanas (Larus dominicanus) $^{40,41,42,43,44,45}$, tucúquere (Bubo magellanicus $)^{46}$, y la paloma (Columbia livia) $)^{17,48}$. Las prevalencias de esta bacteria en las distintas aves varían de 2,6 a $75 \%$ y las técnicas más frecuentemente usadas han sido cultivo bacteriano y reacción de polimerasa en cadena (RPC) con secuenciación de genomas (Tabla 1). El serovar de Salmonella reportado con más frecuencia fue Enteritidis ${ }^{40,42,43,46}$, pero los serovares Agona, Anatum, Havana, Heidelberg, Infantis, Senftenberg y Dublín también fueron documentados ${ }^{40,42,47}$. La evidencia molecular reveló que las aves marinas actúan como reservorios de cepas de $S$. Enteritidis resistentes a los antimicrobianos y, posiblemente, transmiten este patógeno a las aves de corral y humanos en Chile ${ }^{44,45}$. También se ha encontrado resistencia a los antimicrobianos en Salmonella spp en colonias de pingüinos de Magallanes en la Patagonia chilena y en aves acuáticas en el norte y centro de Chile ${ }^{40,47}$. Además, las gaviotas de Franklin que pasan el invierno en la costa chilena transportan Escherichia coli resistente a antimicrobianos, en una proporción mayor que los congéneres del hemisferio norte ${ }^{49,50}$. Un estudio más reciente, determinó que los búhos del centro de Chile podrían actuar como reservorios ambientales de bacterias resistentes, incluyendo Salmonella enterica serovar Infantis altamente virulenta, que produce ESBL resistente a una amplia variedad de antimicrobianos, metales pesados y desinfectantes ${ }^{46}$. Diferentes estudios indican que las actividades antropogénicas en áreas naturales y urbanas, como el turismo y la contaminación debida a la eliminación inadecuada de desechos y el tratamiento de aguas residuales, pueden resultar en la liberación de Salmonella resistente a los antimicrobianos al medio ambiente, exponiendo a las aves silvestres a infecciones con el riesgo de transmisión a especies co-existentes ${ }^{47,49,51}$.

\section{Campylobacter}

Las aves silvestres son reservorios importantes de Campylobacter spp, patógeno zoonótico que causa gastroenteritis en humanos en todo el mundo ${ }^{52}$. La bacteria no produce daño en aves silvestres y habita en su tracto gastrointestinal como un comensal ${ }^{53}$. Su principal mecanismo de transmisión a los seres humanos es a través de la ingestión de alimentos contaminados de origen animal, particularmente aves de corral ${ }^{54}$. Las aves silvestres pueden jugar un papel en la transmisión de Campylobacter spp. al entrar en contacto con granjas de animales y propagar el patógeno por medio de sus excrementos y/o a través de la contaminación de fuentes de agua ${ }^{55,56}$. También existe riesgo de transmisión a humanos en áreas urbanas donde las aves silvestres mantienen el patógeno ${ }^{57}$.

Se han aislado cuatro especies de Campylobacter en aves silvestres chilenas: Campylobacter jejuni, Campylobacter coli, Campylobacter upsaliensis y Campylobacter lari $^{14,15,58,59}$. Los registros de Campylobacter han sido realizados durante los últimos 30 años, principalmente utilizando cultivos bacterianos y, en su mayoría, por el mismo grupo de investigación ${ }^{14,15,58,59}$. Más recientemente, Campylobacter ornithocola sp. nov. se describió como una nueva especie aislada de aves urbanas en Chile ${ }^{60}$. La información sobre el papel de las aves silvestres en la transmisión de Campylobacter a las aves de corral y los seres humanos en Chile es actualmente inexistente. Se han analizado diferentes especies de aves frente a esta bacteria y las prevalencias, por lo mismo, han sido muy variables, oscilando entre 0 y $100 \%$ (ver Tabla 1 ).

\section{Patógenos aviares desatendidos en Chile}

Esta sección enumera los patógenos de aves que han recibido poca o ninguna atención por parte de la comunidad científica en Chile, pero que son relevantes para la salud pública, la conservación de la vida silvestre o la producción animal.

El primer estudio sobre patógenos en aves silvestres en Chile fue realizado por García y Lagunas en $1941^{61} \mathrm{e}$ incluyó la evaluación del cólera aviar (Pasteurella multocida) en aves marinas, aunque no se mencionan nombres específicos de aves infectadas. Después de este estudio, se evaluó la presencia de $P$. multocida en pingüinos de Humboldt (Spheniscus humboldti), pero no se encontró individuo infectado alguno ${ }^{62}$. Esta bacteria ha causado eventos de muertes masivas en aves coloniales en otros lugares y podría tener consecuencias importantes para ciertas especies ${ }^{63}$. La información disponible sobre el cólera aviar en Chile está desactualizada y es necesario investigar la presencia de este patógeno en las poblaciones de aves silvestres, particularmente en las especies de aves acuáticas $^{64}$. De manera similar, la viruela aviar (poxvirus) se identificó en la torcaza (Patagioenas araucana, un 
positivo de 3 analizados) y el jote de cabeza colorada (Cathartes aura, un individuo analizado) mediante evaluación macroscópica e histopatología ${ }^{16,65}$. La viruela aviar es capaz de causar una alta mortalidad y morbilidad en algunas aves, en particular los columbiformes ${ }^{66}$. Sin embargo, los casos de poxvirus aviar se han descrito de forma poco frecuente en el país y no hay información sobre el efecto de este patógeno en las poblaciones afectadas.

La enfermedad de Newcastle (paramixovirus-1 aviar, APV-1) causa importantes pérdidas económicas para la industria avícola en todo el mundo cada año ${ }^{67}$. No se han documentado casos de enfermedad de Newcastle en Chile desde $1977^{68}$. Actualmente, el país se encuentra en una favorable condición sanitaria, declarandose libre de este virus con vacunación con virus vivo. El APV-1 fue prospectado en cormoranes neotropicales (Phalacrocorax brasilianus) aplicando métodos moleculares, sin embargo, no se encontró animal alguno infectado con el virus ${ }^{69}$. Los paramixovirus aviares están probablemente presentes en aves silvestres, ya que los estudios evidenciaron la exposición a diferentes tipos (incluido APV-1) en palomas ${ }^{48}$, águila (Geranoaetus melanoleucus), caracara (Caracara plancus), lechuza blanca (Tyto alba), tucuquere (Bubo magellanicus) y nuco (Asio flammeus) ${ }^{70}$.

Listeria monocytogenes ha sido escasamente investigada en Chile y no hay estudios que evalúen otros patógenos cosmopolitas relevantes en aves silvestres, tales como Erysipelothrix rhusiopathiae y Clostridium perfringens, a pesar de su importancia para la salud pública $^{71,72}$. La tuberculosis aviar (complejo Mycobacterium avium) no se ha detectado en aves silvestres en Chile, y recientemente se realizó un estudio en rapaces sin registrar animales positivos a la infección ${ }^{73}$. Esta enfermedad no plantea riesgos para los seres humanos sanos; sin embargo, podría ser una amenaza para pacientes intensamente inmunocomprometidos al ser éstos susceptibles a la infección ${ }^{74}$.

Chlamydia psittaci es un patógeno presente en aves psitaciformes y capaz de causar la psittacosis en humanos $^{75}$. A pesar de esto, ha sido ampliamente ignorado en
Chile ya que no existen estudios dirigidos de $C$. psittaci en aves silvestres, particularmente en especies nativas de Psittaciformes. Un solo estudio, realizado en Chillán, ha documentado la exposición a este patógeno en $11 \%$ de las palomas capturadas en entornos urbanos que fueron incluidas en este estudio (diagnosticadas por ELISA) ${ }^{16}$. Las actividades ilegales, como el comercio y la tenencia de animales silvestres, ponen en riesgo la salud humana debido al potencial contacto con animales silvestres infectados y la amenaza de transmisión de enfermedades zoonóticas $^{74}$. Estas actividades ilegales son un conflicto recurrente para las autoridades chilenas y constituyen un problema de salud pública relevante, tanto para los infractores como para las autoridades de inspección (Servicio Agrícola y Ganadero, SAG) ${ }^{77}$. Por esta razón, los estudios destinados a evaluar la presencia de C. psittaci y otros patógenos en aves psitaciformes confiscadas y en libertad, así como determinar el riesgo de exposición humana a estos patógenos, corresponden a estudios de relevancia que permiten salvaguardar la salud humana en Chile.

\section{Conclusiones}

La información sobre la mayoría de las enfermedades infecciosas en Chile es insuficiente. Sólo en los últimos años algunos patógenos en aves silvestres, como influenza aviar y Salmonella spp, han recibido más atención de la comunidad científica, ya que se han realizado estudios moleculares detallados para caracterizar mejor los agentes virales y bacterianos de estos patógenos. Sin embargo, es necesario un mayor esfuerzo para identificar correctamente los agentes patógenos presentes en las aves silvestres y el impacto potencial que podrían tener en su salud. Además, es extremadamente importante evaluar el papel de las aves silvestres como reservorio de patógenos que podrían representar una amenaza para la producción animal y los sistemas de salud pública en Chile.

Agradecimientos. Agradecemos al proyecto FONDECYT $\mathrm{n}^{\mathrm{o}} 1170972$.

\section{Referencias bibliográficas}

1.- Scott M E. The impact of infectious disease on animal populations, implications for conservation biology. Cons Biol 1988; 2: 40-65 doi: 10.1111/j.1523-1739.1988.tb00334.x.

2.- Daszak P, Cunningham A A, Hyatt A D. Emerging infectious diseases of wildlifethreats to biodiversity and human health. Science 2000; 287 (5452): 443-9. doi: 10.1126/ science.287.5452.443.

3.- Smith K F, Sax D F, Lafferty K D. Evidence for the role of infectious disease in species extinction and endangerment. Conserv Biol 2006; 20: 1349-57. doi: 10.1111/j.15231739.2006.00524.x.

4.- Pedersen A B, Jones K E, Nunn C L, Altizer $\mathrm{S} A$. Infectious diseases and extinction risk in wild mammals. Conserv Biol 2007; 21 (5): 1269-79. doi: 10.1111/j.15231739.2007.00776.x.

5.- Epstein P R. Climate change and emerging infectious diseases. Microbes Infect 2001; 3 (9): 747-54. doi: 10.1016/S1286-4579(01)01429-0.

6.- Binder S, Levitt A M, Sacks J J, Hughes J M. Emerging infectious diseases: public health issues for the 21 st century. Science 1999; 284 (5418): 1311-13. doi: 10.1126/ science.284.5418.1311

7.- Jones K E, Patel N G, Levy M A, Storeygard A, Balk D, Gittleman J L, Daszak P. Global trends in emerging infectious diseases. Nature 2008; 451: 990-3. doi: 10.1038/nature06536.

8.- Fuller T, Bensch S, Muller I, Novembre J, Pérez-Tris J, Ricklefs R E, et al. The ecology of emerging infectious diseases in migratory birds: an assessment of the role of climate change and priorities for future research. Ecohealth 2012; 9 (1): 80-8. doi: 10.1007/s10393-012-0750-1. 
9.- Reed K D, Meece J K, Henkel J S, Shukla S $\mathrm{K}$. Birds, migration and emerging zoonoses: West Nile virus, Lyme disease, influenza $A$ and enteropathogens. Clin Med Res 2003; 1 (1): 5-12. doi: 10.3121/cmr.1.1.5.

10.- Reid A H, Taubenberger J K, Fanning T G. Evidence of an absence: the genetic origins of the 1918 pandemic influenza virus. Nat Rev Microbiol 2004; 2 (11): 909-14. doi: 10.1038/ nrmicro1027.

11.- Barbosa A, Palacios M J. Health of Antarctic birds: a review of their parasites, pathogens and diseases. Polar Biol 2009; 32 (8): 1095. doi: 10.1007/s00300-009-0640-3.

12.- Kerry K R, Riddle M. Health of Antarctic wildlife: a challenge for science and policy. Springer Science \& Business Media. New York. 2009.

13.- Moher D, Liberati A, Tetzlaff J, Altman DG. Preferred reporting items for systematic reviews and meta-analyses: the PRISMA statement. Ann Intern Med 2009; 151 (4): 264 9. doi: 10.7326/0003-4819-151-4-20090818000135 .

14.- Fernández H, Gesche W, Montefusco A, Schlatter R. Wild birds as reservoir of thermophilic enteropathogenic Campylobacter species in southern Chile. Memórias do Instituto Oswaldo Cruz 1996; 91 (6): 699-700. doi: 10.1590/S0074-02761996000600007.

15.- Fernández H, Vera F, Villanueva M P. Especies de Arcobacter y Campylobacter en aves y mamíferos del sur de Chile. Arch Med Vet 2007; 39 (2): 163-5. doi: 10.4067/S0301732X2007000200011.

16.- Cubillos A, Schlatter R, Cubillos V. Diftero viruela aviar en torcaza (Columba araucana, Lesson) del Sur de Chile. Zentralblatt für Veterinärmedizin Reihe B 1979; 26 (5): 430-2. doi: 10.1111/j.1439-0450.1979.tb00834.x.

17.- González-Acuña D, Silva F, Moreno L, Cerda F, Donoso S, Cabello J, et al. Detección de algunos agentes zoonóticos en la paloma doméstica (Columba livia) en la ciudad de Chillán, Chile. Rev Chilena Infectol 2007; 24 (3): 199-203. doi: 10.4067/S071610182007000300004

18.- Bullock DS. Vultures as disseminators of anthrax. The Auk 1956; 73 (2): 283-4. doi: $10.2307 / 4081485$.

19.- Suarez DL. Evolution of avian influenza viruses. Vet Microbiol 2000; 74 (1-2): 15-27. doi: 10.1016/S0378-1135(00)00161-9Get.

20.- Sturm-Ramirez K M, Hulse-Post D J, Govorkova E A, Humberd J, Seiler P, Puthavathana $\mathrm{P}$, et al. Are ducks contributing to the endemicity of highly pathogenic $\mathrm{H} 5 \mathrm{~N} 1$ influenza virus in Asia? J Virol 2005; 79 (17): 11269-79. doi: 10.1128/JVI.79.17.1126911279.2005.

21.- Clark L, Hall J. Avian influenza in wild birds: status as reservoirs, and risks to humans and agriculture. Ornithol Monogr 2006; 2006 (60): 3-29. doi: $10.2307 / 40166825$.

22.- Webster RG, Bean WJ, Gorman OT, Chambers TM, Kawaoka Y. Evolution and ecology of influenza A viruses. Microbiol Rev 1992; 56 (1): 152-79. PMID: 1579108.

23.- Li K S, Guan Y, Wang J, Smith G J D, Xu K M, Duan L, et al. Genesis of a highly pathogenic and potentially pandemic $\mathrm{H} 5 \mathrm{~N} 1$ influenza virus in eastern Asia. Nature 2004; 430: 209-13. doi: 10.1038/nature02746.

24.- Suárez D L, Senne D A, Banks J, Brown I H, Essen S C, Lee C W, et al. Recombination resulting in virulence shift in avian influenza outbreak, Chile. Emerg Infect Dis 2004; 10: 693-9. doi: 10.3201/eid1004.030396.

25.- Spackman E, McCracken K G, Winker K, Swayne D E. H7N3 Avian influenza virus found in a South American wild duck is related to the Chilean 2002 poultry outbreak, contains genes from equine and North American wild bird lineages, and is adapted to domestic turkeys. J. Virol 2006; 80(15): 7760-4. doi: 10.1128/ JVI.00445-06.

26.- Beato M S, Capua I. Transboundary spread of highly pathogenic avian influenza through poultry commodities and wild birds: a review. Rev Sci Tech Off Int Epizoot 2011; 30 (1): 51 61. doi: 10.20506/rst.30.1.2013.

27.- Rojas H, Moreira R, Avalos P, Capua I, Marangon S. Avian influenza in poultry in Chile. Vet Rec 2002; 151 (6): 188. PMID: 12201269.

28.- Mathieu C, Moreno V, Retamal P, González A, Rivera A, Fuller J, et al. Pandemic (H1N1) 2009 in breeding turkeys, Valparaíso, Chile. Emerg Infect Dis 2010; 16(4): 709-11. doi: 10.3201/eid1604.091402.

29.- Jiménez-Bluhm P, Di Pillo F, Bahl J, Osorio J, Schultz-Cherry S, Hamilton-West C. Circulation of influenza in backyard productive systems in central Chile and evidence of spillover from wild birds. Prev Vet Med 2018; 153: 1-6. doi: 10.1016/j. prevetmed.2018.02.018.

30.- Jiménez-Bluhm $P$, Bravo-Vásquez $N$, Torchetti M, Killian M, Livingston B, Herrera J, et al. Low pathogenic avian influenza (H7N6) virus causing an outbreak in commercial Turkey farms in Chile. Emer Infect Dis 2019; 8: 47985. doi: 10.1080/22221751.2019.1595162.

31.- Mathieu C, Moreno V, Pedersen J, Jeria J, Agredo M, Gutiérrez C, et al. Avian influenza in wild birds from Chile, 2007-2009. Virus Res 2015; 199: 42-45. doi: 10.1016/j. virusres.2015.01.008

32.- Mathieu C, González A, García A, Johow M, Badia C, Jara C, et al. H7N6 low pathogenic avian influenza outbreak in commercial turkey farms in Chile caused by a native South American lineage. Transbound Emerg Dis 2019; 1-11. doi: 10.1111/tbed.13166.
33.- Jiménez-Bluhm $P$, Karlsson E A, Freiden $P$, Sharp B, Pillo F, Osorio J E, et al. Wild birds in Chile harbor diverse avian influenza A viruses. Emerg Microbes Infect 2018; 7 (1): 1-4. doi: 10.1038/s41426-018-0046-9.

34.- Coburn B, Grassl G A, Finlay B B. Salmonella, the host and disease: A brief review. Immunol Cell Biol 2007; 85 (2): 112-8. doi: 10.1038/ sj.icb.7100007.

35.- Daust P Y, Busby D G, Ferns L, Golst J, McBurney S, Poppe C, Whhitney H Salmonellosis in songbirds in the Canadian atlantic provinces during winter-summer 1997-98. Can Vet J 2000; 41 (1): 54-9. PMC:1476332.

36.- Fernández J, Fica A, Ebensperger G, Calfullan H, Prat S, Fernández A, et al. Analysis of molecular epidemiology of Chilean Salmonella enterica serotype Enteritidis isolates by pulsedfield gel electrophoresis and bacteriophage typing. J Microbiol 2003; 41(4): 1617-22.

37.- Hendriksen R S, Vieira A R, Karlsmose S, Lo Fo Wong D M, Jensen A B, Wegener H C, et al. Global monitoring of Salmonella serovar distribution from the World Health Organization Global Foodborne Infections Network Country Data Bank: results of quality assured laboratories from 2001 to 2007. Foodborne Pathog Dis 2011; 8 (8): 887-900. doi: 10.1089/fpd.2010.0787.

38.- Barreto M, Castillo-Ruiz M, Retamal P. Salmonella enterica: una revision de la trilogy agente, hospedero y ambiente, $\mathrm{y}$ su trascendencia en Chile. Infectol Dia 2016; 33 (5): 547-57. doi: 10.4067/S071610182016000500010.

39.- Tauni M A, Ósterlund A. Outbreak of Salmonella typhimurium in cats and humans associated with infection in wild birds. J Small Anim Pract 2000; 41(8): 339-41. doi: 10.1111/ j.1748-5827.2000.tb03214x.

40.- Fresno M, Barrera V, Gornall V, Lillo P, Paredes N, Abalos P, et al. Identification of diverse Salmonella serotypes, virulotypes, and antimicrobial resistance phenotypes in waterfowl from Chile. Vector Borne Zoonotic Dis 2013; 13 (12): 884-7. doi: 10.1089/ vbz.2013.1408

41.- Toro M, Retamal P, Allard M, Brown E W, Evans P, González-Escalona N. Draft genome sequences of 33 Salmonella enterica clinical and wildlife isolates from Chile. Genome Announcs 2015; 3(2): e00054-15. doi: 10.1128/ genomeA.00054-15.

42.- López-Martín J, Junod T, Riquelme F, Contreras C, González-Acuña D. Detección de especies de Salmonella y Mycobacterium en gaviotas dominicanas (Larus dominicanus) y gaviotas de Franklin (Leucophaeus pipixcan) en la ciudad de Talcahuano, Chile. Rev Med Chile 2011; 139 (11): 1496-502. doi: 10.4067/S003498872011001100017. 
43.- Rodríguez F, Moreno J, Ortega R, Mathieu C, García A, Cerda-Leal F, et al. Evidence for Kelp Gulls (Larus dominicanus) and Franklin's Gulls (Leucophaeus pipixcan) as carriers of Salmonella by real-time polymerase chain reaction. J Wild Dis 2012; 48 (4): 1105-8. doi: 10.7589/2012-04-104.

44.- Retamal P, Fresno M, Dougnac C, Gutiérrez S, Gornall V, Vidal R, et al. Genetic and phenotypic evidence of the Salmonella enterica serotype Enteritidis human-animal interface in Chile. Front Microbiol 2015; 6: 464. doi: 10.3389/ fmicb.2015.00464.

45.- Toro M, Retamal P, Ayers S, Barreto M, Allard M, Brown E W, et al. Wholegenome sequencing analysis of Salmonella enterica serovar Enteritidis isolates in Chile provides insights into possible transmission between gulls, poultry, and humans. Appl Environ Microbiol 2016; 82 (20): 6223-32. doi: 10.1128/AEM.01760-16.

46.- Fuentes-Castillo D, Farfán-López M, Espósito F, Moura Q, Fernandes M R, Lopes R, et al. Wild owls colonized by international clones of extended-spectrum $\beta$-lactamase (CTX-M)-producing Escherichia coli and Salmonella Infantis in the Southern Cone of America. Sci Total Environ 2019; 674: 554-62. doi: 10.1016/j.scitotenv.2019.04.149.

47.- Dougnac C, Pardo C, Meza K, Arredondo C, Blank O, Abalos P, et al. Detection of Salmonella enterica in Magellanic penguins (Spheniscus magellanicus) of Chilean Patagonia: evidences of inter-species transmission. Epidemiol Infect 2014; 143 (6): 1187-93. doi: 10.1017/S0950268814002052.

48.- Toro H, Saucedo C, Borie C, Gough R E, Alcaíno H. Health status of free-living pigeons in the city of Santiago. Avian Pathol 1999; 28 (6): 619-623. doi: 10.1080/03079459994416.

49.- Hernández J, Johansson A, Stedt J, Bengtsson S, Porczak A, Granholm S, et al. Characterization and comparison of extendedspectrum $\beta$-lactamase (ESBL) resistance genotypes and population structure of Escherichia coli isolated from Franklin's gulls (Leucophaeus pipixcan) and humans in Chile. PLoS one 2013; 8 (9): e76150. doi: 10.1371/ journal.pone.0076150.

50.- Bonnedahl J, Stedt J, Waldenström J, Svensson L, Drobni M, Olsen B. Comparison of extended-spectrum $\beta$-lactamase (ESBL) CTX-M genotypes in Franklin gulls from Canada and Chile. PLoS One 2015; 10 (10): e0141315. doi: 10.1371/journal.pone.0141315.

51.- Retamal P, Llanos-Soto S, Salas L M, López J, Vianna J, Hernández J, et al. Isolation of drugresistant Salmonella enterica serovar Enteritidis strains in gentoo penguins from Antarctica. Polar Biol 2017; 40 (12): 2531-6. doi: 10.1007/ s00300-017-2163-7.
52.- Humphrey T, O’Brien S, Madsen M. Campylobacters as zoonotic pathogens: a food production perspective. Int J Food Microbiol 2007; 117 (3): 237-57. doi: 10.1016/j. ijfoodmicro.2007.01.006.

53.- Hepworth P J, Ashelford K E, Hinds J, Gould K A, Witney A A, Williams N J, et al. Genomic variations define divergence of water/wildlife associated Campylobacter jejuni niche specialists from common clonal complexes. Environ Microbiol 2011; 13 (6): 1549-60. doi: 10.1111/j.1462-2920.2011.02461.x.

54.- Sheppard S K, Dallas J F, Strachan N J, MacRae M, McCarthy N D, Wilson D J, et al. Campylobacter genotyping to determine the source of human infection. Clin Infect Dis 2009; 48 (8): 1072-8. doi: 10.1086/597402.

55.- Zimmer M, Barnhart H, Idris U, Lee M D. Detection of Campylobacter jejuni strains in the water lines of a commercial broiler house and their relationship to the strains that colonized the chickens. Avian Dis 2003; 47(1): 101-7. doi: 10.1637/0005-2086(2003)047[0101:DOCJ SI]2.0.CO;2.

56.- Keller J I, Shriver W G, Waldenström J, Griekspoor P, Olsen B. Prevalence of Campylobacter in wild birds of the midAtlantic region, USA. J Wild Dis 2011; 47 (3): 750-4. doi: 10.7589/0090-3558-47.3.750.

57.- French N P, Midwinter A, Holland B, Collins-Emerson J, Pattison R, Colles F, et al. Molecular epidemiology of Campylobacter jejuni isolates from wild-bird fecal material in children's playgrounds. Appl Environ Microbiol 2009; 75 (3): 779-83. doi: 10.1128/ AEM.01979-08.

58.- Fernández H. Species and biotype distribution of thermotolerant Campylobacters in animal reservoirs in Southern Chile. Rev Inst Med Trop São Paulo 1988; 30 (5): 357-60. doi: 10.1590/S0036-46651988000500005.

59.- Fernández H, Landskron E, Figueroa G, Gesche W, Montefusco A. Campylobacter laridis: first clinical isolation and identification of reservoir in Chile. Rev Med Chil 1990; 118(6): 699-701. PMID: 1775794

60.- Cáceres A, Muñoz I, Iraola G, Díaz-Viraqué F, Collado L. Campylobacter ornithocola sp. nov., a novel member of the Campylobacter lari group isolated from wild bird faecal samples. Int J Syst Evol Microbiol 2017; 67: 1643-9. doi: 10.1099/ijsem.0.001822.

61.- García J, Lagunas L. Epidemia de cólera en los patos marinos. Rev Med Vet (Buenos Aires) 1941; 23: 145-9.

62.- Schlatter R P, Paredes E, Ulloa J, Harris J, Romero A, Vásquez J, et al. Mortandad de pingüino de Magallanes (Spheniscus magellanicus) en Queule, Región de la Araucanía, Chile. Bol Chil Ornitol 2009; 15(2): 78-86. http://www.aveschile.cl/wp-content/ uploads/2019/03/03.pdf.
63.- Descamps S, Jenouvrier S, Grant Gilchrist H G, Forbes M R. Avian cholera, a threat to the viability of an arctic seabird colony? PLoS one 7 (2): e29659 doi 10.1371/journal. pone. 0029659 .

64.- Friend M. Field manual of wildlife diseases. Madison: National Wildlife Health Center; 1999. $425 \mathrm{p}$.

65.- Mora-Carreño M, Guerra-Correa C, Moroni M, Paredes E. Avian pox in a turkey vulture (Cathartes aura) from northern Chile. Austral J Vet Sci 2019; 51: 41-3. doi: 10.4067/S071981322019000100108

66.- Medina F M, Ramírez G A, Hernández A. Avian pox in white-tailed laurel-pigeons from the Canary Islands. J Wild Dis 2004; 40(2): 351-5. doi: 10.7589/0090-3558-40.2.351.

67.- Dimitrov K M, Afonso C L, Yu Q, Miller P J. Newcastle disease vaccines-a solved problem or a continuous challenge? Vet Microbiol 2017; 206: 126-36. doi: 10.1016/j. vetmic.2016.12.019.

68.- Burbano L A, Van Schaik G, Ernst S, Rojas H. Riesgo de introducción de la enfermedad de Newcastle a Chile por la importación de avestruces. Arch Med Vet 2005; 37(1): 55-9. doi: 10.4067/S0301-732X2005000100008.

69.- Verdugo C, Pinto A, Ariyama N, Moroni M, Hernández C. Molecular identification of avian viruses in Neotropic cormorants (Phalacrocorax brasilianus) in Chile. J Wild Dis 2018; 55(1): 105-12.

70.- González-Acuña D G, Gaete Á, Moreno L, Ardiles K, Mathieu C, Ortega R. Anticuerpos séricos contra la enfermedad de Newcastle e influenza aviar en aves rapaces de Chile. Rev MVZ Córdoba 2012; 17(3): 3118-24. doi: 10.21897/rmvz.210.

71.- Robson J M, McDougall R, Van Der Valk S, Waite S D, Sullivan J J. Erysipelothrix rhusiopathiae: an uncommon but ever present zoonosis. Pathology 1998; 30(4): 391-4. doi: 10.1080/00313029800169686.

72.- Tsiodras S, Kelesidis T, Kelesidis I, Bauchinger U, Falagas ME. Human infections associated with wild birds. J Infect 2008; 56(2): 83-98. doi: 10.1016/j. jinf.2007.11.001.

73.- Moroni M, Salgado M, Albornoz A, Tejeda C, Alvarado-Rybak M. Molecular evidence for Mycobacterium bovis infection in wild Chilean hawk (Accipiter chilensis). Austral J Vet Sci 2018; 50(2): 115-7. doi: 10.4067/S071981322018000200115.

74.- Nightingale S D, Byrd L T, Southern P M, Jockusch J D, Cal S X, Wynne B A. Incidence of Mycobacterium aviumintracellulare complex bacteremia in human immunodeficiency virus-positive patients. J Infect Dis 1992; 165(6): 1082-5. doi: 10.1093/ infdis/165.6.1082.

75.- Beeckman D S A, Vanrompay D C G. 
Zoonotic Chlamydophila psittaci infections from a clinical perspective. Clin Microbiol Infect 2009; 15(1): 11-7. doi: 10.1111/j.14690691.2008.02669.x.

76.- Karesh W B, Cook R A, Gilbert M, Newcomb J. Implications of wildlife trade on the movement of avian influenza and other infectious diseases. J Wildl Dis 2007; 43(3): S55-S59. http://globalraptors.org/grin/ researchers/uploads/200/wildlife_trade.pdf.

77.- González-Hein G. Estudio serológico de Chlamydophila psittaci, Salmonella spp, virus pox aviar, adenovirus y virus polioma en aves del orden psitaciforme en cautiverio en Chile Central [dissertation]. [Santiago]: Universidad de Chile; 2006. 104 p. http://repositorio. uchile.cl/bitstream/handle/2250/130847/ Estudio-serol\%c3\%b3gico-de-Chlamydophilapsittaci\%2c-Salmonella\%20spp.\%2c-virusPox-aviar\%2c-adenovirus-y-virus-polioma-enaves-del-orden-Psittaciforme-en-cautiverio-enChile-central.pdf? sequence $=1 \&$ isAllowed $=\mathrm{y}$

78.- Toro H, Pavez EF, Gough RE, Montes G, Kaleta EF. Serum chemistry and antibody status to some avian pathogens of free living and captive condors (Vultur gryphus) of central
Chile. Avian Pathol 1997; 26 (2): 339-45. doi: 10.1080/03079459708419216.

79.- Seguel M, González-Acuña D, Mathieu C, Hernández C, Paredes E. Immunosuppressive syndrome in juvenile black-faced ibises (Theristicus melanopis melanopis) in southern Chile. Avian Dis 2012; 56 (3): 611-5. doi: 10.1637/9956-100611-Case.1.

80.- Hanson B A, Luttrell M P, Goekjian V H, Niles L, Swayne D E, Senne D A, et al. Is the occurrence of avian influenza virus in Charadriiformes species and location dependent? J Wild Dis 2008; 44 (2): 351-61. doi: 10.7589/0090-3558-44.2.351.

81.- Collado L, Jara R, González S. Description of Helicobacter valdiviensis sp. nov., an Epsilonproteobacteria isolated from wild bird faecal samples. Int J Syst Evol Microbiol 2014; 64 (6): 1913-9. doi: 10.1099/ ijs.0.057141-0.

82.- Schlatter R, Reinhardt G, Burchard L. Estudio del jote (Coragyps atratus foetens, Lichtenstein) en Valdivia: Etologia carroñera y rol en diseminación de agentes patógenos. Arch Med Vet 1978; 10: 110-27. https://books. google.cl/books?hl=es\&lr=\&id=0fiQYfw7xA
$8 \mathrm{C} \&$ oi $=$ fnd $\&$ pg $=$ PA $111 \&$ ots $=$ DiXTaiRLFS $\&$ sig=papjOsVCjSbKSb4iQruRUzIqN9A\&red ir_esc $=\mathrm{y} \# \mathrm{v}=$ onepage \&q\&f$=$ false.

83.- Báez J, Hernández-García M, Guamparito C, Díaz S, Olave A, Guerrero K, et al. Molecular characterization and genetic diversity of ESBL-producing Escherichia coli colonizing the migratory Franklin's gulls (Leucophaeus pipixcan) in Antofagasta, North of Chile. Microb Drug Resist 2015; 21 (1); 111-6. doi: $10.1089 / \mathrm{mdr} .2014 .0158$.

84.- Ardiles-Villegas K, González-Acuña D, Waldenström J, Olsen B, Hernández J. Antibiotic resistance patterns in fecal bacteria isolated from Christmas shearwater (Puffinus nativitatis) and masked booby (Sula dactylatra) at remote Easter Island. Avian Dis 2011; 55 (3). 486-9. doi: 10.1637/9619-122010-ResNote.1.

85.- Seguel M, Moroni M, Gomez M, Hernández C, Paredes E. Bacterial meningoencephalitis in a free Chimango Caracara (Milvago chimango temucoensis). Braz J Vet Pathol 2012; 5 (1); 16-9. https://bjvp.org.br/wp-content/ uploads/2015/07/DOWNLOAD-FULLARTICLE-4-20881 $2012 \quad 3 \quad 30 \_13 \quad 45 . p d f$ 